\title{
Information Technology Sourcing Changes in an SME: Ça Va de Soi in the Cloud with Diamonds
}

\section{Forthcoming in Journal of Information Technology Teaching Cases}

\section{(August 2017)}

\section{The final publication is available at Springer via:}

\author{
https://doi.org/10.1057/s41266-017-0023-5
}

\section{Simon Bourdeau, PH.D. UQÀM}

\author{
Dragos Vieru, PH.D. \\ TÉLUQ University
}

\begin{abstract}
This case study presents the information technology (IT) sourcing decisions made by a Canadian small and medium enterprise (SME) specializing in knitwear, called Ça Va de Soi (CVDS), during the deployment of the second phase of their two-phase organizational strategy based on a "Bricks and Clicks" business model. CVDS has 30 employees and 5 stores with annual sales of around \$CDN 5 million (2015). The case focuses on phase two, the "Clicks", where an IT project, divided into two parallel subprojects, was realized: 1) the custom development of an ERP system, and 2) the creation of an online e-commerce. The project was based on an "onpremises" sourcing strategy where the information systems were developed "in-house" by external service providers. After several months of efforts, the subprojects were abandoned and CVDS' activities were rolled back to their legacy systems (Part A). Pulling the plug on the IT project was a tough decision for CVDS who still needed the online store to be implemented in order to support its stores' activities. However, CVDS' management team considered this failure as an opportunity to learn from their mistakes, review and transform its IT sourcing strategy (Part B).
\end{abstract}

Keywords: Small and medium enterprise (SME), IT project failure, IT sourcing Strategy, SaaS, Organizational vision, Partner selection. 


\section{Part A - “On-Premises"}

\section{Ça Va de Soi: A Bricks and Clicks Business Model}

"The initial IT investment focused on developing a customized online store and ERP, hosted and maintain in-house. It was a beautiful dream adapted to our needs." Nathalie Giroux, Ça Va de Soi's web store manager.

"Developing a customized solution was too complex and demanding for a SME like ours. We just didn't have the expertise, experience and financial resources to support such endeavor. We had to pull the plug and change our approach. I think that, where we are now and where we want to go, we really have no choice but to change our sourcing strategy. It's clearly a transition in this organization." Marie-Lou Joli, Ça Va de Soi's accountant and process specialist

Ça Va de Soi (CVDS hereafter) ${ }^{1}$ is a family-owned and managed small and medium enterprise (SME) located in Montreal, Quebec, Canada. This company specializes in the design, distribution, and sale of knitwear. CVDS focuses on classic European garments and has a wide variety of products.

The company products are high-end in terms of raw material and finishes. It has access to the same natural raw materials and yarn used by international brands such as Prada, Gucci, Louis Vuitton, Hermès and Chanel. Like its competitors, CVDS stands out for the quality of the raw materials used in its products and its control of the finishes. Its products are timeless, classic, modern and multi-purpose, which go to all ages. CVDS manages over 750 styles, with an average of five colors and three sizes for each style. However, in terms of price, the company is positioned in the middle market since CVDS sells its products at a third of the price of its international competitors. CVDS is associated with the "slow fashion" ${ }^{2}$ movement.

\footnotetext{
${ }^{1}$ http://www.cavadesoi.com/

2 The slow fashion movement picks up on the spirit of the slow food movement, encouraging environmentally friendly processes with timeless style (Jung, S., \& Jin, B. (2014). A theoretical investigation of slow fashion: sustainable future of the apparel industry. International journal of consumer studies, 38(5), 510-519)
} 


\section{History and New Business Model}

CVDS was founded in $1972^{3}$ by Odile and Antoine Nasri ${ }^{4}$. At the beginning, it specialized in the design, production and wholesaling of knitted garments. Since its inception, CVDS had always paid a lot of attention to quality, both in manufacturing and in the design of its products. In 1988, the company strengthened its position in the premium products market and adopted a mission to design products with a "soul". In 1996, CVDS started sourcing its yarn, the raw material for its clothes, from Italy.

In the early 2000s, with the opening of international markets and changes in consumers' habits, CVDS faced a significant sales reduction. Facing dramatic market changes, such as competitors' development of multi-brand businesses in various locations and new product placement strategies in these locations, CVDS decided in 2004 to reorient its activities to target the highend segments of the market and to focus only on noble materials, such as Egyptian cotton, cashmere and superfine Merino. With this strategic reorientation came the deployment of a two-phase organizational strategy based on the "Bricks and Clicks" business model. In phase one, the "Bricks", CVDS opened five physical stores and developed its brand image. In phase two, the "Clicks", CVDS developed and deployed an online store. As mentioned by the web store manager, Nathalie:

"It was just a new and inevitable reality. All companies nowadays sell online. Not selling online kind of gives a weird impression."

\footnotetext{
${ }^{3}$ Appendix A presents a timeline of the main decisions and events in CVDS's history.

${ }^{4}$ Appendix B presents a brief description of CVDS's employees and the members of the management team.
} 
This new business model also meant that CVDS abandoned most of its wholesale activities. The "Bricks" phase deployment started with the opening of CVDS' first store on Laurier Avenue in Montreal in 2006. This marked the beginning of the direct sales model for the company. It also involved the development and implementation of a new marketing strategy based on educating consumers about fibre quality and high-end knitting expertise. During the next 7 years, CVDS opened four more stores in Montreal, Ottawa, Quebec City, and Toronto. CVDS' head office is located in the Mile End neighborhood in Montreal and it serves as a design studio, warehouse and distribution center for its stores.

\section{Three Business Cycles since Ça Va de Soi's Inception}

From the owner's perspective, CVDS has been through three business cycles since its creation. The first cycle, labelled "product mastering," lasted from the company's inception to the early 2000s. During this cycle, CVDS focused on mastering its products and procurement activities. It had developed knowledge and know-how of the design and manufacturing of its products and identified and selected specialized high-end raw materials while developing preferential relationships with a small but loyal group of spinners ${ }^{5}$ and manufacturers. Once the owner felt the company had finally mastered its products, CVDS embarked on the next cycle.

The second business cycle, labelled "customer mastering," lasted from 2002-03 to 2013. This cycle is associated to the "Bricks" phase of CVDS' strategy and was characterized by the opening of the five stores. This reorientation meant that CVDS needed to change several of its main

\footnotetext{
5 "Spinners" are the textile manufacturers who convert the fibre, such as cotton and wool, into yarn and fabric. Spinning is a process in which fibres are converted by passing through certain processes like blow room, carding, drawing, combing, simplex, ring frame and finally winding into yarns (Wikipedia).
} 
processes such as logistics, inventory management, accountability, hiring and training. However, the main transformation was related to customer relationships. Now, with its stores, CVDS was in direct contact with its customers. The company had to learn how to develop long-lasting relationships, which meant approaching the customers and capturing and storing information about them. Further, new activities had to be learned and rolled out such as merchandising, customer service, catalogue preparation, etc. After almost ten years of building solid relationships with its customers CVDS felt confident to embark on its third business cycle, based on e-commerce technologies.

The third business cycle, labelled "e-commerce mastering," began in 2013. The main goal was to implement a B2C transactional website. As mentioned by Antoine, "the online store will be our larger showcase." To launch an integrated online store, CVDS needed to develop and implement in parallel an Enterprise Resource Planning (ERP) system to support the websitebased transactions. The ERP would allow CVDS to better manage its inventory by documenting all its products (i.e., detailed descriptions and photographs) and identifying where to automatically locate each product among the various stores and the warehouse. This was not possible with CVDS' legacy inventory systems, i.e. MBI, FashionCart, Raymark ${ }^{6}$, which were old and not integrated. In addition, the online store would be supported by a CRM system that would enable CVDS to assess the impact of the online sales on international markets, facilitate return management by integrating product data, and broadcast the image of a high-end brand. Thus, this transformation would ultimately help CVDS to acquire better management

\footnotetext{
${ }^{6}$ At CVDS, there are three main inventory systems: (1) Raymark is the point-of-sale and inventory system in the stores, (2) FashionCart is used in the stores and at the warehouse to place orders, and (3) MBI is used in the warehouse to manage inventory. Appendix C presents a detailed description of these three systems and CVDS's existing IT infrastructure.
} 
information and allow it to optimize its procurement process by investing in the right inventory at the right time.

\section{Ça Va de Soi's Two-Pillar Business Strategy}

The company's first business strategy pillar is to offer a quality product in terms of material and know-how at a reasonable price. CVDS puts a lot of effort and resources into the research and development of its products. Since its inception more than 40 years ago, Antoine, the owner, has travelled around the globe several times to find the best raw materials and develop privileged relationships with a limited number of spinners and manufacturers. Over time, most of the spinners have entered in partnership with CVDS in two manufacturing plants that produce CVDS' products.

To offer its products at reasonable prices, CVDS has eliminated the hidden costs associated with marketing. This explains why CVDS never launches any self-advertising campaigns and invests instead in a bi-annual catalogue that is sent to its customers to inform them about the value of the company and its products' qualitative aspects, such as yarn sourcing and manufacturing know-how. The underlying goal of the catalogue is to promote "Ça Va de Soi's philosophy": high-quality products and exceptional know-how.

The second business strategy pillar is related to CVDS' employees and its customer service. It is a priority for CVDS' management team to continuously assess and improve customer service in its stores network. The company emphasizes relationship management with its employees, having weekly meetings with all the store managers and bi-annual offsite meetings with all the 
company's employees. For CVDS, it is important that all employees believe in the company's product philosophy. The working environment is characterized by openness and a lack of hierarchy. As several employees mentioned, they are not afraid to share ideas and express their views because they know their opinions will be heard. As a store manager alleged:

"He [Antoine, the owner] is very open. He listens to everybody, he wants to hear ideas, and he wants to know what a person thinks. Yes, he is very attentive. Each time there is an issue or a problem, he wants to communicate with employees to make the best decision possible."

\section{Business Vision of Ça Va de Soi's Owner}

The way CVDS has evolved over time in terms of organizational culture and working environment has been influenced by Antoine Nasri's vision. In his view, to be successful in the knitwear industry, three intertwined key elements must be present.

First, you need to have a quality product in terms of material and design/manufacturing knowhow. This is a necessary condition but not a sufficient one. Second, you need to have the best human resources available and surround yourself with exceptional individuals, who must be creative but should also act with integrity and passion for the product. Finally, it is essential to master every aspect of your business, e.g. product mastering or customer mastering, before launching new and major initiatives. These initiatives should be clear and aligned with the rest of the company's activities and should not compromise the quality of either the product or the employees' work. For instance, in the early 2000s, the decision to change CVDS' sales channel from wholesales to retail was based on more than 25 years of accumulated experience on design, manufacturing and procurement of knitwear clothing. Thus, CVDS' team could focus then on learning the activities and challenges associated with retailing. 


\section{Information Technology at Ça Va de Soi: Context and Constraints}

Since its inception, CVDS activities have been supported by information technology (IT). The company invests annually between $1.5 \%$ and $2 \%$ of its turnover in IT, which is a strong ratio in the fashion industry ${ }^{7}$.

CVDS' management team strongly believes in Web-based systems and open-source software for the development and management of its future online store. These technologies would allow CVDS to minimize its dependence on external IT consultants and give more flexibility for future changes. However, CVDS remains an SME, that is, it had always faced challenges and constraints such as limited capabilities to expand its IT resources, limited access to IT skills and reliance on external IT expertise. Therefore, at CVDS the prioritization of IT investments seemed to be based more on a spur-of-the moment approach, and the company had no hardware replacement policy. In terms of IT staff, even though most employees were young and comfortable with new technologies, ${ }^{8}$ only one part-time employee had the skills to do the maintenance of only one system (Raymark) of the three main inventory systems used by CVDS. An external IT consultant, Fadi, provided the rest of the IT support and development. Over the last decade, Fadi has developed a friendly relationship with Antoine.

The three inventory systems (MBI, FashionCart, Raymark) and the accounting system, QuickBooks, were not integrated in the existing IT infrastructure. This implied that the same

\footnotetext{
${ }^{7}$ Diagnostic report on CVDS' digital capacity realized by VESTECHPRO (https://vestechpro.com/en/) with the collaboration of CEFRIO.

${ }^{8}$ Most of CVDS's employees are under 35 years old, are very familiar with digital tools and are enthusiastic about new IT.
} 
data had to be separately entered in each system, manually. These systems, which have been developed and implemented by external consultants, had not been regularly updated. As for the data backup, a daily backup was done automatically at the stores through the Raymark system but no automatic backups were done at the head office.

\section{Information Technology Strategy at Ça Va de Soi}

Since 2006, CVDS has grown from one to five stores. With one store, it was possible for CVDS to continue using paper to support business activities, but with five stores, CVDS needed to move to electronic support. While now offering a wide variety of products, some of CVDS stores were not able to stock all of them because of physical space limitations. Sometimes customers had specific requests from the company catalogue and, if the product was not available in the stores, CVDS lost sales opportunities.

The strategy established by CVDS to guide the development and implementation of the new IT infrastructure (the online store and the ERP) was clear: in the short term, the new IT infrastructure would enable CVDS to consolidate its operations and maximize sales at its five stores. This goal was important because, since their openings, the stores' sales have increased consistently. The online store would also enable CVDS to restart its wholesale activities, which have been dormant for more than a decade, by developing B2B relations with retailers. In the long term, this new IT infrastructure would give CVDS the prospect of offering franchise opportunities. Indeed, the deployment of a new IT infrastructure would force CVDS to review and formalize its business processes at a granular level. With the growth of its stores' sales, combined with a great potential of expansion of online sales, CVDS' management team realized 
that the company could no longer operate in a context where roles and responsibilities were not clearly defined, operating mode was reactive, and operations planning lacked rigor.

CVDS' management team was convinced that having an online store would allow the company to capture all sales opportunities and offer customers living far from the stores the possibility of buying CVDS' products. It would also help store employees to efficiently manage all 750 product styles CVDS offers. With an online store, employees would start a transaction on an electronic tablet and complete it on the point-of-sale (POS) system where they would print the invoice. The online store would also give the management team access to consolidated management information such as product margins, sales trends, product returns, and inventory levels. This information, not generated by the legacy systems, is essential to analyze sales opportunities, better place products in stores, and develop new products. By the end of 2012, CVDS' management team realized that the company had reached the end of its second cycle and time had come to initiate the third phase of the organizational strategy: the development and deployment of a transactional B2C website. As Antoine put it,

"Now that we have mastered what we do and mastered our product, the online store will be an opportunity to review and simplify our structure and processes and focus on the essentials."

\section{Ça Va de Soi's IT Project - First Attempt}

At the beginning of 2013, it was decided by CVDS' management team that their online store would be their sixth one, and like any other brick-and-mortar store, it would have its own sales 
and management teams, budget and objectives. As formulated by Kinza, the VP merchandising and marketing, IT project manager and the owners' daughter:

"The online store is perceived as a complementary 'tool' to first, support the stores' activities and second, raise the brand's profile. The website will be a good tool to gather everything and see everything in one place."

\section{IT Project's Objectives, Anticipated Benefits and Challenges}

The development and implementation of the transactional website along with a new ERP, would allow CVDS to achieve certain objectives. First, the new infrastructure would simplify data management and thus allow employees to focus on key activities such as selling, customer service and support, new product/market development, etc. Second, with access to more accurate, up-to-date management information, CVDS' management team would be able to make the better decisions and be more efficient. Third, by being able to sell online, it would give CVDS the opportunity to enter new markets (e.g. United States, Europe, and Japan). Finally, the new online store would allow CVDS to be a more independent brand, which means having better control over its own channels for direct sales to consumers.

CVDS anticipated an increase in sales by giving direct access, via its new transactional website, to its existing customers but also to new international customers. As Kinza, the VP merchandising and marketing, stated:

"The e-commerce platform will help our sales. It will give confidence to the girl who sells in the store to say: 'I am sure I didn't miss anything that I could have offered to the customer.' Major efforts were also deployed in the development of the platform to provide an online experience which would be as close as possible to the store experience while being complementary to the stores." 
CVDS also expected, through better access to available inventory information, to make better purchasing decisions and thus reduce its inventory. With the new systems, all product data would be cleaned out and indexed in various identification categories, which would facilitate access to management information. In addition, by having more precise product and sales information, CVDS would be able to grow its margin because it would be able to reduce certain costs, better adjust product prices and have greater bargaining power with suppliers. As Kinza put it, this information would become "the 'mind' of our product".

A major challenge associated with this IT project was CVDS' lack of internal IT expertise, meaning the company had to rely on outsourced IT expertise. To mitigate this risk, Kinza who was put in charge of the IT project, self-trained and sought advice from external IT specialists. An informal assessment of CVDS employees' digital competences was also realized to identify the IT skills gaps. Finally, a project steering committee, which included CVDS' management team, was established.

\section{An IT Project based on Two Interrelated IT Subprojects}

The IT project, which started late 2013, was structured around two interrelated subprojects: (1) the development of an ERP system and (2) the deployment of a B2C transactional website. The ERP system, which was created by a consultancy firm called INBIZ ${ }^{9}$, a small firm from Ottawa, was supposed to be custom developed for CVDS' needs. It was the largest project ever

\footnotetext{
${ }^{9}$ http://www.inbizerp.com/
} 
undertaken by INBIZ. The ERP system's main objectives were to standardize and computerize CVDS' processes, as well as, to link with the new transactional website. It was supposed to:

1. Give access in real time to inventory in stores and in the warehouse/distribution center,

2. Document all CVDS' products,

3. Interface with the accounting system (QuickBooks) by using application programming interfaces (API),

4. Create links between the distribution center and its stores,

5. Assess online international sales,

6. Support return activities, and

7. Facilitate product life cycle management.

The $\mathrm{B} 2 \mathrm{C}$ transactional website was developed on Magento ${ }^{10}$, an open-source e-commerce platform. Fly Conseil, ${ }^{11}$ a Web agency located in Montreal, configured Magento's templates to meet CVDS' needs. The objectives of the online store were to: 1) project the image of a highend brand name with a unique know-how; and 2) present CVDS' product philosophy to domestic and international customers. The main functionalities of the e-commerce platform were shopping cart, integration with CVDS' inventory (in stores and warehouse), CRM and direct integration with Moneris financial system for payments and with FedEx for delivery.

\section{IT Project's Business Partners Selection}

The initial outset date was November 2013 with a delivery date after six months. The approach was to implement the two subprojects in parallel. For the first subproject (the ERP), INBIZ selection as the outsourcing service supplier was based on the recommendations of Fadi, CVDS' external consultant and the owner's friend. The decision to select INBIZ was made by Antoine who relied on Fadi's recommendation who had a friend working for INBIZ. Even though Kinza

\footnotetext{
${ }^{10}$ http://magento.com/

11 http://www.flyconseils.com/
} 
had approached various SMEs to get advices regarding IT projects and had developed an evaluation grid to help CVDS' management team during the service provider selection, she had no saying in this matter, as no formal selection process was done and no due diligence was performed. INBIZ was a small and inexperienced consultancy firm. It received the responsibility of developing and testing the new ERP system, migrating data from CVDS' legacy systems to the ERP, and developing the necessary interfaces with Magento, the e-commerce platform.

The other subproject was the development of the transactional B2C online store. This time, to select the vendor, CVDS went through a rigorous selection process by: 1) identifying a list of ecommerce platforms and consultancy firms; 2) meeting with those firms and have platforms' demonstrations; and 3) evaluating each platform and consultancy firm using an evaluation grid. The outcome was that Fly Conseil, an experienced web agency with more than 600 web-related projects realized, was selected to configure and deploy the online store. Magento was preferred because it was open-source-based and it had been successfully used by other companies for years. Fly Conseil was responsible for configuring Magento based on CVDS' requirements, ensuring that the interfaces between the new ERP and Magento were functional.

\section{The Project Failure}

From the outset of the project, the development of the ERP was very challenging for both CVDS and INBIZ. Several of these challenges stemmed from the discovery of important operational limits associated with 1) INBIZ's technological platform on which the ERP was developed (e.g. INBIZ's platform supported only one warehouse) and with 2) INBIZ's lack of appropriate expertise and experience to undertake a complex project such as the one at CVDS. 
Nonetheless, the ERP was officially launched on August 1, 2014 after more than four months of delay. Most delays were due to technical problems faced by INBIZ in developing a customized ERP. INBIZ had put a lot of pressure on CVDS to agree to launch the system even though the interfaces with the e-commerce platform were not yet developed. Right from the beginning, CVDS was confronted with both technical and managerial difficulties. First, INBIZ realized it was unable to develop bridges between the ERP and the Magento platform. Second, there were recurrent technical problems, such as incorrect end-of-the-day revenues and sales, inventory mistakes, missing or unapplied sales taxes, non-functional interface buttons, etc. This situation forced CVDS to use a "parallel" deployment strategy involving the use of both INBIZ's ERP and CVDS' legacy systems simultaneously for several weeks. This meant that employees had to double enter all their transactions in both systems. Around the same date, CVDS launched the Magento-based transactional website. However, the new website was in a standalone mode, without any links to the ERP system or to any inventory system, therefore, useless for CVDS' needs. Finally, in early November 2014, Antoine made a bold decision:

"You know what, we're putting our store activities in danger, we're putting our employees' confidence at risk, we're asking our employees to use a system that doesn't work properly and we're all tired. We should do things differently. Enough with this ERP, let's stop, pull the plug and take a break."

The IT project was abandoned and CVDS' activities were rolled back to their legacy systems. However, at that point CVDS was in a difficult situation: the customized ERP development project had failed but the online store needed to grow and to support the stores' activities. 


\section{Case Part A: Discussion Questions}

Your task is to build a compelling recommendation to the CVDS' management team. To get you

started, consider the following discussion questions:

1. Analyze Strategy: If you were CVDS' owner, what would be your strategy for the development and implementation of the online store? Would you use the same "onpremises" sourcing strategy?

2. Alternatives: What could be the other options? Identify and suggest alternative strategies.

3. Recommendation: Knowing that CVDS' growth depends on the deployment of its online store, which strategy would you recommend in this situation? Justify your answer. 


\section{Appendix A. Timeline of Main Events in CVDS' History}

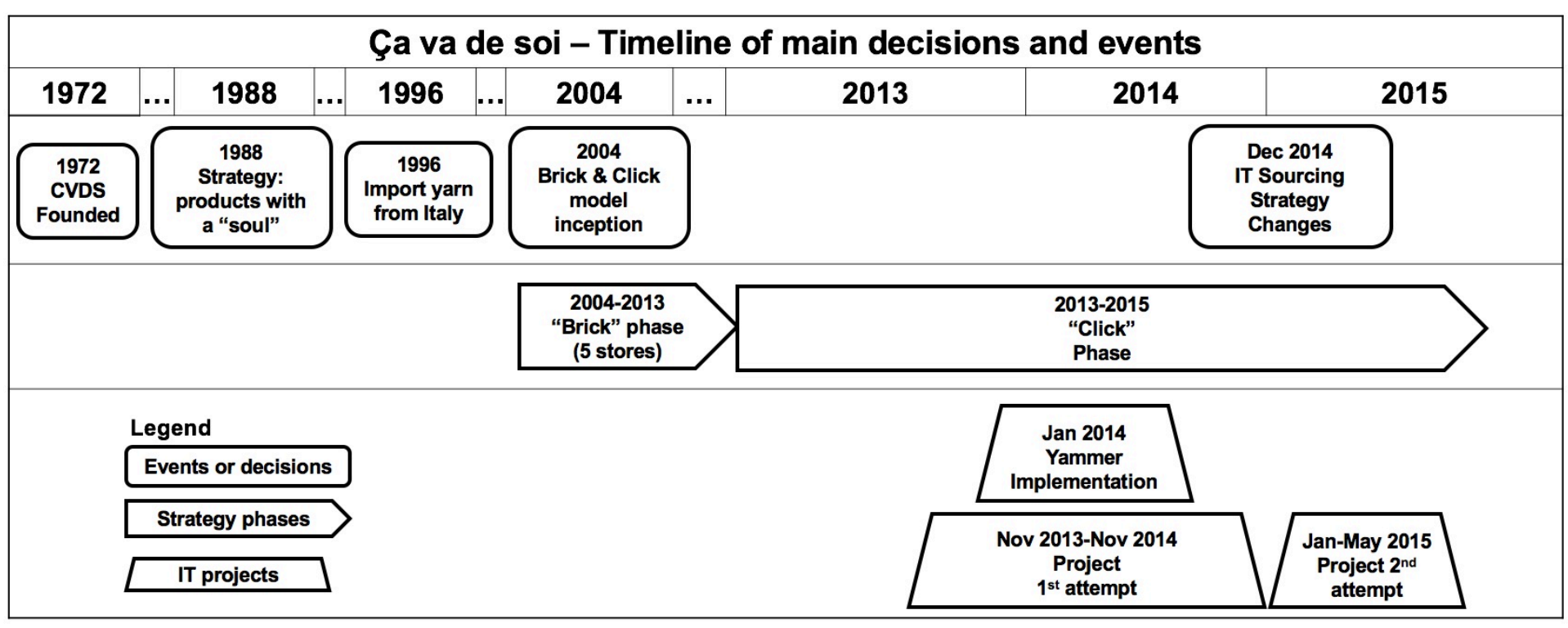




\section{Appendix B. CVDS' Stakeholders}

\begin{tabular}{|c|c|c|c|}
\hline Names & Functions & Tasks Descriptions & $\begin{array}{l}\text { Management } \\
\text { Team }\end{array}$ \\
\hline $\begin{array}{l}\text { Antoine } \\
\text { Nasri }\end{array}$ & $\begin{array}{l}\text { - Founder } \\
\text { - Owner of CVDS }\end{array}$ & $\begin{array}{l}\text { - In charge of product design, supplier/manufacturer } \\
\text { relationships, finance and budget approvals }\end{array}$ & $\mathbf{X}$ \\
\hline Fadi & $\begin{array}{l}\text { - External IT } \\
\text { consultant }\end{array}$ & $\begin{array}{l}\text { - In charge of maintenance and evolution of CVDS's IT } \\
\text { infrastructure }\end{array}$ & \\
\hline $\begin{array}{l}\text { Geneviève } \\
\text { Labrosse }\end{array}$ & - Store manager & $\begin{array}{l}\text { - Montreal regional manager and head of training for } \\
\text { the two stores in Montreal }\end{array}$ & \\
\hline $\begin{array}{l}\text { Gabrielle } \\
\text { Nasri }\end{array}$ & $\begin{array}{l}\text { - VP operations } \\
\text { - VP HR }\end{array}$ & $\begin{array}{l}\text { - In charge of human resource management, store } \\
\text { operations, training and internal communications }\end{array}$ & $\mathbf{X}$ \\
\hline $\begin{array}{l}\text { Gonzales } \\
\text { Elpidio }\end{array}$ & $\begin{array}{l}\text { - Warehouse } \\
\text { manager }\end{array}$ & $\begin{array}{l}\text { - In charge of logistics and warehouse } \\
\text { - Manages inventory levels }\end{array}$ & \\
\hline $\begin{array}{l}\text { Kinza } \\
\text { Nasri }\end{array}$ & $\begin{array}{l}\text { - VP merchandising } \\
\text { - VP marketing }\end{array}$ & $\begin{array}{l}\text { - In charge of marketing strategy, such as campaign } \\
\text { management, web strategy, social networks, etc. } \\
\text { - IT project manager }\end{array}$ & $\mathbf{x}$ \\
\hline $\begin{array}{l}\text { Marc-Olivier } \\
\text { Joly Comptois }\end{array}$ & - Warehouse clerk & $\begin{array}{l}\text { - Warehouse and logistics employee } \\
\text { - In-house specialist in Raymark system }\end{array}$ & \\
\hline $\begin{array}{l}\text { Marie-Lou } \\
\text { Joly }\end{array}$ & $\begin{array}{l}\text { - Accountant } \\
\text { - Process specialist }\end{array}$ & $\begin{array}{l}\text { - In charge of accounting and formalizing business } \\
\text { processes }\end{array}$ & $\mathbf{x}$ \\
\hline $\begin{array}{l}\text { Nathalie } \\
\text { Giroux }\end{array}$ & $\begin{array}{l}\text { - Web store } \\
\text { manager }\end{array}$ & $\begin{array}{l}\text { - In charge of the web platform: product entry, data } \\
\text { analysis, serving online customers, etc. }\end{array}$ & \\
\hline $\begin{array}{l}\text { Odile Bougain } \\
\text { Nasri }\end{array}$ & $\begin{array}{l}\text { - Founder of CVDS } \\
\text { - Head of marketing }\end{array}$ & - In charge of CVDS stores and branding & $\mathbf{x}$ \\
\hline $\begin{array}{l}\text { Stephanie } \\
\text { Boridy }\end{array}$ & - Content manager & $\begin{array}{l}\text { - In charge of content management (newsletter, web) } \\
\text { - Manages social media campaigns and blog }\end{array}$ & \\
\hline
\end{tabular}




\section{Appendix C. CVDS' Information Technology Infrastructure (before the IT projects)}

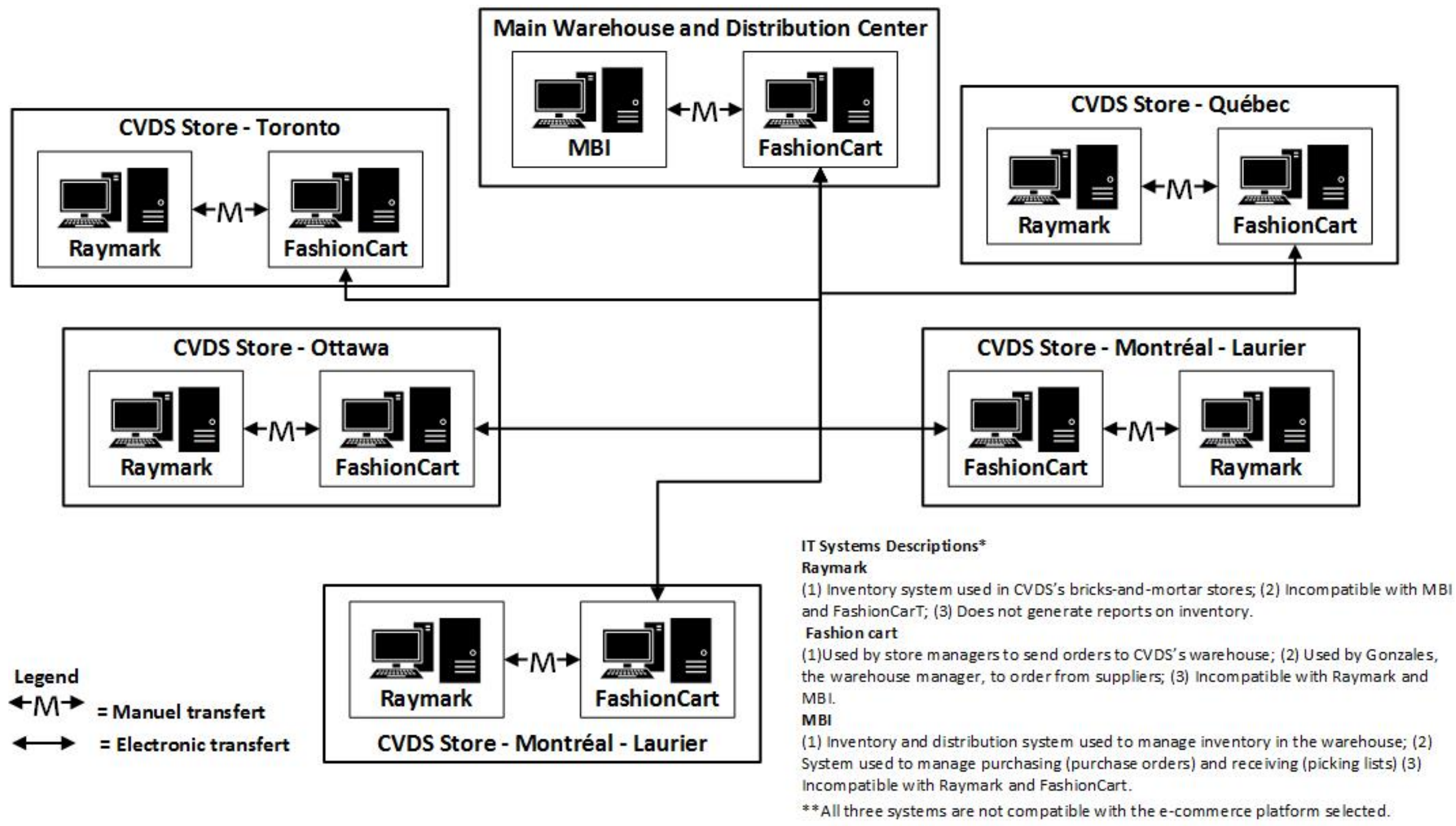




\section{Part B - “Cloud-Based"}

\section{From "On-Premises" to "Cloud-Based" Sourcing Strategy}

"Our goal with this new approach was to deploy, gradually, a web based platform host in the cloud by service providers. A solution where we pay for the services used where we can do about everything ourselves with little technical background and where we keep control over data. So far, so good!!!"

Kinza Nasri, VP merchandising and marketing, IT project manager and owners' daughter

In December 2014, one month after decommissioning of INBIZ's ERP and rolling back to the legacy systems, CVDS' management team decided that they should resuscitate the IT project. The initial idea was still relevant and CVDS badly needed an online store to support its growth. In January 2015, the team decided to reactivate the project, but this time based on a different approach. CVDS decided that they would launch a "standalone" e-commerce platform with no integration with CVDS' inventory legacy systems. To do so, CVDS would use standardized templates provided by a cloud-based sourcing solution provider to support the online store. For this second attempt, CVDS management teams decided that things would be done differently based on the lessons learned from the previous failure.

\section{The IT Project Failure as a Trigger to Change the Sourcing Strategy}

The first lesson CVDS' management team learned from the failed IT project was to work progressively while simplifying the changes involved and to have a complete control over the project tasks. For CVDS, this meant separating the IT project into smaller, manageable phases, and deploying them one at the time in a logical sequence. The second lesson learned was that CVDS' management team will have to rigorously select their business partners in the future by evaluating pros and cons of each services provider and technological platform. Finally, the most 
important lesson learned concerned the CVDS' sourcing strategy. The company learned the hard way that developing a customized system, hosted and maintained in-house, could be a very demanding and risky task, especially for an SME. For its future projects, CVDS decided that it would choose a cloud-based, configurable system based on standardized templates proposed by software as a service (SaaS) providers. Templates will only need to be configured to adapt to a specific organizational context, whereas in their failed IT project, the whole software package had to be custom developed for CVDS' needs. As mentioned by Nathalie Giroux, the web store manager:

"We just wanted something simple because simplicity sells. We wanted to remove all the fancy stuff. We wanted to keep the essential and use a standardized template that is beautiful, clean and that works."

\section{Software as a Service Sourcing Strategy: Advantages for an SME}

By simplifying the system's functionalities, by targeting software providers that offer SaaS business models and by using standardized, cloud-based templates, CVDS' new online store would be easier to maintain and evolve. To use sourcing cloud-based solutions such as SaaS, SMEs only need reliable Internet connections and basic IT equipment (e.g. computers, cell phones, tablets) with web browsers. Furthermore, the development, deployment and maintenance would be transferred to the service provider in this business model. As mentioned by Kinza:

"With our new sourcing strategy, we host the data, we own the data. After all, LightSpeed [the SaaS provider selected by CVDS] is just a platform that we use to process data. We pay a monthly membership to use their applications. If we are not pleased with their services, we take our data, we say 'thank you and goodbye' and we transfer them to another service provider's platform." 
By changing from an "on-premises", where CVDS' IT infrastructure was managed and developed internally, to a "SaaS" sourcing approach, this new sourcing strategy would facilitate the identification and prioritization of CVDS' future needs. The company would use a more stable applications platform that has been previously tested and populated. The employees would have access to data and applications from anywhere at any moment. Furthermore, since the web communities around SaaS solutions such as LightSpeed and Magento are large and well established, it is relatively easy to get online support and/or training. It would also simplify CVDS' IT management needs: minimize the IT costs and risks while spreading them over a longer period. Additionally, Kinza mentioned that "with SaaS agreement, you are not stuck with long terms agreements, you have more flexibility".

For CVDS' management team, the new sourcing approach also meant modifying CVDS governance structure in terms of decision-making process, control and accountability. While in the previous approach (on-premises sourcing), its IT infrastructure maintenance, and applications licensing and upgrade would have been done "in-house", in the cloud-based approach CVDS will just pay the SaaS provider for all the necessary IT services. The company just wanted to keep the ownership of their key asset, its customer data. This is reflected by Kinza:

"The biggest strategy changes come from the fact that CVDS realized that, what is important for us is to keep control over our data, not over the applications."

An important effect of adopting a SaaS approach was that CVDS management team would have to change its focus from managing an IT staff to managing relationships and contracts with the cloud services provider. With the "on-promises" strategy, most of CVDS focus was on managing their relation with Fadi, CVDS' IT infrastructure adviser and developer. With a cloud-based sourcing strategy, CVDS management team would have to establish an appropriate contract and 
follow-up on how service level agreements are respected. In this situation, CVDS management team would also have to face other important issues such as deciding if it would be more appropriate to go for a single service provider or multiple ones? Would it be more appropriate to be selective in identifying which IT service to outsource, or should it opt for a total outsourcing approach? CVDS management team would also have to decide between long term and short term contracts. The SaaS sourcing approach was not totally new for CVDS. A few months before launching the failed IT project, CVDS implemented an enterprise social network application called Yammer ${ }^{12}$.

\section{Yammer Implementation: A Key Trigger of the Sourcing Strategy Change}

At the beginning of 2014, before launching the ERP and online store project, CVDS management team decided to implement a SaaS-based private social network application called Yammer. The idea behind this small project was to stimulate communication between employees and facilitate mutual assistance during the implementation of the ERP and the online store. As CVDS' network of stores grew over the years, it had become increasingly difficult to share the enterprise's values and culture. By implementing Yammer, CVDS' goal was to increase the exchanges between employees, facilitate the flow of ideas, foster collaboration, and create a sense of clan spirit.

"Yammer is like a kind of Facebook but for businesses. It has profiles for each person, we 'like' another person to follow him or her, groups can be created, so each store has its group, and training videos can easily be distributed,"

(Gabrielle, HR and operations VP).

\footnotetext{
12 https://www.yammer.com/
} 
Yammer was one of main drivers of the decisional process of sourcing change. Yammer is an application that relies on a SaaS business model, meaning that licensing and delivery is on a subscription basis and is centrally hosted by Yammer. To activate the service, only a simple configuration is required. At CVDS, the configuration was done by Kinza, who oversaw this small IT project, with the help of Marie-Lou, the accountant.

At the beginning of 2014, Marie-Lou presented the Yammer application to the store managers. Since most of CVDS' employees are under 35 and social media savvy, no prior training was required. As stated by a store manager: "We were told 'go ahead, use it, try it, express yourself, experiment, post pictures, things that you like. Explore it and see how it works.'" A few weeks later, a two-day meeting with all store managers was held to share impressions and suggest improvements. During the meeting the participants co-created a list of "rules" and "procedures" regarding how Yammer should be used at CVDS. These rules and procedures were then disseminated to all employees through Yammer.

Since its successful implementation in February 2014, all employees have used Yammer for most of their communications. Several advantages for using Yammer were identified. First, Yammer required very limited financial and technological investments. Second, Yammer was a platform that efficiently enabled the communication among employees. By installing this application, CVDS gave a signal to its employees that their ideas and comments are important to the company. Third, the company used this preliminary project to evaluate employees' motivation and readiness for the upcoming IT change. Finally, the Yammer project allowed CVDS' management team to explore and experiment with a new sourcing approach and assess 
its advantages and disadvantages in order to reduce CVDS' dependency on Fadi, the external IT consultant. As mentioned by Mari-Lou:

"With a cloud-based solution, you don't need to be a technical genius or rely on an IT specialist because everything is online now, you pay for the service, you limit the needs, you give access and that's about it".

\section{Ça Va de Soi's IT Project - Second Attempt}

\section{Selecting Business Partners}

In January 2015, CVDS' management team launched the "stand-alone" e-commerce platform development project. To accomplish that, it was decided that the company needs to identify a reliable and trusted sourcing service provider. During the post-mortem meetings following the IT project failure, the management team realized that the transactional website, which has been originally developed by Fly Conseil, was efficient and operational. However, it could not be launched due to the lack of bridges with the ERP system that was developed by INBIZ. Thus, it was decided that Fly Conseil, who knew CVDS' internal operations and had an impressive track record, would remain their business partner. More precisely, it was decided that the Magentobased transactional website developed by Fly Conseil would be used in the new stand-alone ecommerce approach.

Then, CVDS' management team had to select the inventory solution and a sourcing service provider that would support the online store. To be operative, CVDS stand-alone e-commerce platform needed a point-of-sale (POS) system to support the online transactions and manage 
the inventory. After evaluating several POS solutions and service providers, LightSpeed's ${ }^{13}$ webbased POS solution was selected because it was found to be reliable, simple, and it used preconfigured templates. Furthermore, in addition to supporting CVDS' online store, LightSpeed's POS could potentially be implemented in all CVDS' physical stores. This would provide the necessary integration between the "brick" stores and the "click" store. Before signing the agreements, CVDS' management team validated that bridges between LightSpeed's POS and Magento's platform could be developed. HyperSpace, a California-based middleware firm specialized in developing such bridges, was contacted and a meeting to evaluate its expertise and experience was scheduled.

CVDS' management decided that Hyperspace would configure LightSpeed's POS to CVDS' needs by using standardized templates without any customized development. Once the configuration completed, the management of the LightSpeed's POS would be transferred back to CVDS and Nathalie, the web store manager, would use a content management system (CMS) to update and support CVDS' online store. Then, CVDS would pay a monthly fee to use the LightSpeed's online POS. Hyperspace was also mandated to develop bridges with Magento in collaboration with Fly Conseil. Before launching this collaboration, Kinza, organized a preliminary meeting between representatives of all companies to clarify each firm's roles and responsibilities as well as to evaluate their mutual trust.

"I will not sign a contract with anyone before all parties have proved to me that they are committed to work with each other because they have lots of interdependencies in that project" (Kinza)

\footnotetext{
${ }^{13}$ https://www.lightspeedhq.com/ LightSpeed's POS system is used by more than 24,000 organizations worldwide.
} 
The service level agreement was co-signed by CVDS, LightSpeed, Fly Conseil and HyperSpace in which each party's roles and responsibilities were clearly identified. In this contract, it was also made clear that CVDS kept the control over their data which would be hosted on servers controlled by CVDS' management team.

\section{Successful Deployment of a Cloud-Based Online Store}

CVDS' stand-alone e-commerce platform development took place between February and May 2015. CVDS' online store, developed in collaboration between Fly Conseil and HyperSpace, was a combination of a transactional website developed on Magento's cloud-based platform with LightSpeed's cloud-based POS. In the first phase of this project, the new online store was separated from CVDS' inventory legacy systems since the integration between CVDS inventory systems and LightSpeed's POS would be done manually by Nathalie, the web store manager. She would also oversee the orders reception and transfer, be in charge of answering customers, and checking inventory levels, etc. Gonzales, the warehouse manager would keep Nathalie informed when a product would go out of stock in the CVDS' legacy inventory systems. She would then manually enter the inventory levels in the LightSpeed system. When a "zero" for an out-of-stock product, would be entered in the LightSpeed's inventory, the Magento ecommerce platform would immediately display an "unavailable" status on the online store. This manual procedure was far from being ideal, but at least it would allow CVDS to control the online selling process without jeopardizing its stores' activities.

In developing a stand-alone e-commerce platform, CVDS not only adopted a new sourcing strategy by choosing an easy-to-use, cloud-based, configurable and reliable system, but it also 
applied a different project governance strategy. While managing the relationship with its cloud services providers, CVDS kept the control over their customer data, a key company asset, which would be hosted on an internal server. By choosing a SaaS solution, CVDS realized that the costs related to the IT acquisition, operation, maintenance, and update were minimized. The company made a smaller financial investment than it has made in the failed project and also minimized its risks. Moreover, since the cloud-based solution is easy to use, CVDS would not need to have specialized IT staff to support its activities.

Following the successful implementation of this project, during the first six months of 2016, CVDS deployed several other SaaS solutions such as Microsoft 365, OneDrive and Skype for business. CVDS' online store, www.cavadesoi.com, was officially launched in May 2015 for a "slow and simple opening" (Nathalie) with limited publicity surrounding the inauguration. The bridges between Magento's e-commerce platform and LightSpeed's POS worked perfectly and only minor adjustments had to be made. As summed up by Kinza:

"I think we have learned to believe in technology and develop confidence as individuals and as a team. We learned to control data, not technology. Because cloud-based solutions are easy to configure, we have a greater control and flexibility over our technological destiny." 


\section{Case Part B: Discussion Questions}

Students can evaluate the advantages and disadvantages of changing the sourcing strategy from "on-premises" to "cloud-based" in a SME context.

1. Analyze the pros and cons of the two IT sourcing strategies: Cloud-based computing and IT outsourcing. Based on your analysis, which of the two sourcing strategies would be more appropriate for an SME like CVDS?

2. What were the lessons learnt from the failed IT project that triggered CVDS' IT sourcing change process?

3. What were the determinant factors that influenced CVDS' management to adopt a cloudbased solution? 